\title{
Nivolumab-induced fulminant diabetic ketoacidosis followed by thyroiditis
}

\author{
Ploutarchos Tzoulis1,*, Richard W Corbett2,*, Swarupini Ponnampalam', Elly Baker1, Daniel Heaton', \\ Triada Doulgeraki ${ }^{3}$ and Justin Stebbing 4
}

1Department of Diabetes, The Whittington Hospital, Whittington Health NHS Trust, London, UK, 2Department of Medicine, Imperial College London, London, UK, 3Medical School, University of Athens, Athens, Greece, and

${ }^{4}$ Department of Surgery and Cancer, Imperial College London, London, UK

Correspondence should be addressed to $\mathrm{P}$ Tzoulis

Email

*(P Tzoulis and R W Corbett contributed equally to this work)

\section{Summary}

Five days following the 3rd cycle of nivolumab, a monoclonal antibody, which acts as immune checkpoint inhibitor against the programmed cell death protein-1, for metastatic lung adenocarcinoma, a 56-year-old woman presented at the hospital critically ill. On admission, she had severe diabetic ketoacidosis (DKA), as evidenced by venous glucose of $47 \mathrm{mmol} / \mathrm{L}$, blood ketones of $7.5 \mathrm{mmol} / \mathrm{L}$, $\mathrm{pH}$ of 6.95 and bicarbonate of $6.6 \mathrm{mmol} / \mathrm{L}$. She has had no personal or family history of diabetes mellitus (DM), while random venous glucose, measured 1 week prior to hospitalisation, was $6.1 \mathrm{mmol} / \mathrm{L}$. On admission, her $\mathrm{HbA} 1 \mathrm{c}$ was $8.2 \%$ and anti-GAD antibodies were $12 \mathrm{kIU} / \mathrm{L}(0-5 \mathrm{kU} / \mathrm{L})$, while islet cell antibodies and serum C-peptide were undetectable. Nivolumab was recommenced without the development of other immune-mediated phenomena until 6 months later, when she developed hypothyroidism with TSH 18U/L and low free T4. She remains insulin dependent and has required levothyroxine replacement, while she has maintained good radiological and clinical response to immunotherapy. This case is notable for the rapidity of onset and profound nature of DKA at presentation, which occurred two months following commencement of immunotherapy. Despite the association of nivolumab with immune-mediated endocrinopathies, only a very small number of patients developing type 1 DM has been reported to date. Patients should be closely monitored for hyperglycaemia and thyroid dysfunction prior to and periodically during immunotherapy.

\section{Learning points:}

- Nivolumab can induce fulminant type 1 diabetes, resulting in DKA.

- Nivolumab is frequently associated with thyroid dysfunction, mostly hypothyroidism.

- Nivolumab-treated patients should be monitored regularly for hyperglycaemia and thyroid dysfunction.

- Clinicians should be aware and warn patients of potential signs and symptoms of severe hyperglycaemia.

\section{Background}

The programmed cell death-1 protein (PD-1) is an immune checkpoint, a cell surface protein found on activated $\mathrm{T}$ cells, which, through interaction with its ligands, PD-L1 and PD-L2, inhibits kinase signalling pathways that normally lead to T-cell activation (1). Several tumour types can evade host immune surveillance by downregulating cytotoxic T-cell signalling through the upregulation of PD-L1 expression (2). This pathway is targeted by anti-PD-1 agents (3). Nivolumab is an anti-PD-1 monoclonal antibody that selectively blocks the interaction of the cancer cell PD-L1 and the PD-1 receptor of the activated T cells; as a result, $\mathrm{T}$ cells, instead 
of undergoing apoptosis, are capable of surviving and help to eliminate cancer cells (3). Therefore, nivolumab acts as an immunomodulatory antibody that ultimately augments the anticancer immune response through downregulation of T-cell inhibition.

Nivolumab was introduced and firstly approved for the treatment of melanoma, but has an increasing role in other tumours such as non-small-cell lung cancer (NSCLC) (4), renal cell carcinoma, head and neck squamous cell carcinoma (HNSCC), Hodgkin's lymphoma and urothelial carcinoma. An improvement in the overall survival in a multicentre, randomised, open-label trial comparing nivolumab to docetaxel formed the basis for approval by the regulatory authorities in 2015 for the use of this drug in previously treated metastatic NSCLC (4).

As immune checkpoint inhibitors enhance T-cell immunity by disrupting the inhibitory signalling for the purpose of an increased anti-tumour response, they also reduce immune tolerance and, thereby cause autoimmune toxicities. These immune-related adverse events affect dermatological, gastrointestinal, hepatic, endocrine and other systems, with the commonest adverse effects being immune-related hepatitis, colitis and pneumonitis. Several immune-mediated endocrinopathies, such as autoimmune thyroid disorders, hypophysitis and adrenal insufficiency, are well recognised. However, only very few cases of type 1 diabetes mellitus (DM) have been reported so far.

The case presented here is notable because of the rapidity of development of type $1 \mathrm{DM}$ in combination with the severity of diabetic ketoacidosis (DKA). In addition, this is the second case ever reported in the literature of autoimmune diabetes and hypothyroidism complicating nivolumab therapy.

\section{Case presentation}

Five days following the 3rd cycle of nivolumab as secondline treatment for metastatic lung adenocarcinoma, a 56-year-old Caucasian woman presented at the hospital critically ill. She was initially diagnosed with nonsmall-cell lung cancer three years ago and treated with pemetrexed and cisplatin. Subsequently, she received pemetrexed as maintenance chemotherapy until it was discontinued due to side effects two months prior to her emergency presentation. At that stage, therapy with nivolumab every 2 weeks was initiated with the patient showing good radiological and clinical response to it.

On admission, she was disorientated, agitated and combative without evidence of haemodynamic compromise and required sedation and intubation to permit assessment and initial resuscitation. She had severe metabolic acidosis predominantly due to diabetic ketoacidosis (DKA), as evidenced by glucose of $47 \mathrm{mmol} / \mathrm{L}$ $(846 \mathrm{mg} / \mathrm{dL})$, blood ketones of $7.5 \mathrm{mmol} / \mathrm{L}, \mathrm{pH}$ of 6.95 and bicarbonate of $6.6 \mathrm{mmol} / \mathrm{L}$.

In retrospect, she reported severe polyuria and polydipsia for the preceding $48 \mathrm{~h}$, while one week prior to presentation, she was clinically well and normoglycaemic with random venous glucose of $6.1 \mathrm{mmol} / \mathrm{L}(110 \mathrm{mg} / \mathrm{dL})$. Apart from metastatic lung adenocarcinoma, she had no personal/family history of DM or other organ-specific autoimmune conditions. Venous glucose had been normal at numerous measurements, while there was no evidence of pancreatic involvement, as evidenced by unremarkable appearances in CT abdomen, which was performed 2 days prior to emergency presentation.

\section{Investigation}

The patient had evidence of acute kidney injury with serum creatinine elevated at $300 \mu \mathrm{mol} / \mathrm{L}$, compared to a baseline of $120 \mu \mathrm{mol} / \mathrm{L}$. Her HbA1c on admission was $8.2 \%$, as seen in Table 1 . She was biochemically euthyroid and had appropriately elevated serum cortisol $>1000 \mathrm{nmol} / \mathrm{L}$. Her adrenal, thyroid peroxidase and islet cell antibodies were undetectable, while anti-GAD antibodies were present at $12 \mathrm{kU} / \mathrm{L}(0-5 \mathrm{kU} / \mathrm{L})$. Serum C-peptide was also inappropriately undetectable. She has not been HLA genotyped.

Biochemical values, prior to, at the time of presentation, and after, are illustrated in Table 1.

\section{Treatment}

She responded well to standard treatment for DKA. In specific, she required infusion of large volumes $(11 \mathrm{~L})$ of isotonic saline over the first $48 \mathrm{~h}$ and continuous intravenous insulin infusion with daily requirements of 72 units in the first $24 \mathrm{~h}$ and 59 units in the subsequent $24 \mathrm{~h}$. She was extubated $24 \mathrm{~h}$ following admission, and her cognitive state normalised. However, at the initial stages of recovery, she was susceptible to unpredictable ketosis. Shortly after conversion to subcutaneous insulin administration on day 3 of hospitalisation, she rapidly developed hyperglycaemia and ketosis with blood glucose of about $20 \mathrm{mmol} / \mathrm{L}$ and ketones of $2.0 \mathrm{mmol} / \mathrm{L}$, requiring reinstatement of intravenous insulin infusion for a few hours. In the following 2 days, blood glucose readings ranged between 2.5 and $21.5 \mathrm{mmol} / \mathrm{L}$. Another episode 
Table 1 Blood biochemical parameters one month and one week prior to, at the time of presentation and one week after discharge.

\begin{tabular}{|c|c|c|}
\hline & 1 month before & 1 week before \\
\hline Glucose (mmol/L) & 5.1 & 6.1 \\
\hline Sodium (mmol/L) & 136 & 141 \\
\hline Potassium (mmol/L) & 4.4 & 4.4 \\
\hline \multicolumn{3}{|l|}{ Urea (mmol/L) } \\
\hline Creatinine $(\mu \mathrm{mol} / \mathrm{L})$ & 122 & 119 \\
\hline Haemoglobin (g/L) & 134 & 131 \\
\hline WCC $\left(\times 10^{9} / \mathrm{L}\right)$ & 6.1 & 5.7 \\
\hline CRP (mg/L) & 1 & 1 \\
\hline \multicolumn{3}{|l|}{$\mathrm{HbA}_{1 c}$} \\
\hline \multicolumn{3}{|l|}{$\mathrm{pH}$} \\
\hline \multicolumn{3}{|l|}{$\mathrm{pCO}_{2}(\mathrm{kPa})$} \\
\hline \multicolumn{3}{|l|}{$\mathrm{pO}_{2}(\mathrm{kPa})$} \\
\hline \multicolumn{3}{|l|}{ Bicarbonate (mmol/L) } \\
\hline \multicolumn{3}{|l|}{ Lactate $(\mathrm{mmol} / \mathrm{L})$} \\
\hline \multicolumn{3}{|l|}{ Chloride (mmol/L) } \\
\hline Ketones (mmol/L) & & \\
\hline
\end{tabular}

\begin{tabular}{ccc}
\hline At the time of presentation & 1 week after \\
\cline { 2 - 2 } 17.0 & 14.2 \\
131 & 140 \\
5.3 & 4.4 \\
22.4 & 4.8 \\
300 & 128 \\
137 & 118 \\
19.1 & 7.9 \\
28 & 5 \\
$8.2(66)$ & \\
6.95 & \\
3.2 & \\
18.4 & \\
6.6 & \\
2.3 & \\
105 & \\
7.5 & \\
\end{tabular}

of short-lived hyperglycaemic ketosis occurred $24 \mathrm{~h}$ later, which rapidly resolved with subcutaneous administration of an additional dose of rapid-acting insulin.

\section{Outcome and follow-up}

After developing fulminant type $1 \mathrm{DM}$ leading to severe DKA, this patient remains insulin dependent. She exhibits significant glycaemic variability and her insulin requirements have gradually increased. One year after her diagnosis with nivolumab-induced type $1 \mathrm{DM}$, she is treated with basal bolus insulin regimen in the form of 24 units of insulin glargine and 1 unit of insulin aspart per $10 \mathrm{~g}$ of carbohydrate with an overall 24 -h insulin requirement of approximately 54 units. Her most recent HbA1c was $9.1 \%$ (76 mmol/L).

Her oncologist recommenced nivolumab therapy 1 month after development of DM, and she has maintained good radiological and clinical response to immunotherapy.

No other immune-mediated phenomena were reported until 6 months following her presentation with DKA when she developed subclinical hypothyroidism with TSH: $11.1 \mathrm{U} / \mathrm{L}$ and normal fT4 of $12.6 \mathrm{pmol} / \mathrm{L}$ (normal range: $12-22 \mathrm{pmol} / \mathrm{L}$ ). Three weeks later, thyroid dysfunction progressed with TSH rising to $18.9 \mathrm{U} / \mathrm{L}$ and fT4 below the lower end of normal range at $11.2 \mathrm{pmol} / \mathrm{L}$. She also developed symptoms, such as fatigue, cold intolerance and weight gain of $3 \mathrm{~kg}$, necessitating initiation of levothyroxine replacement at a dose of $50 \mu \mathrm{g} /$ day. Since then, she remains clinically and biochemically euthyroid on the current $50 \mu \mathrm{g}$ daily dose of levothyroxine.
With respect to the possibility of other autoimmune endocrinopathies, she undergoes periodical testing, which has not shown deficiency of any other anterior pituitary hormones. In specific, most recent serum 09:00 h cortisol was $420 \mathrm{mmol} / \mathrm{L}$, IGF-1: 14.4 (normal range: $5.6-22.9 \mathrm{nmol} / \mathrm{L}$ ) and prolactin $226 \mathrm{U} / \mathrm{L}$ (normal range: 102-496U/L), while FSH and LH remain appropriately elevated at 101.9 IU/L and 62.9 IU/L in keeping with her postmenopausal status.

\section{Discussion}

A few case reports have been published of rapid onset type $1 \mathrm{DM}$ after initiation with anti-PD-1 monoclonal antibody treatment. The largest case series of five patients with an onset of diabetes occurring between 1 and 5 months following the commencement of anti-PD-1 drugs (5) cannot attribute DM to immunotherapy with certainty because of the presence of other risk factors like co-administration of other immunomodulators, the presence of pancreatic metastases and pre-existing type 2 diabetes. The first Asian patient to develop type 1 diabetes with nivolumab therapy was described by Okamoto et al. (6). Our case report as well as other reported cases are characterised by the rapid onset of insulin-dependent DM in close proximity with the initiation of nivolumab. Further cases (7) have been reported primarily in patients in Japan, where fulminant type $1 \mathrm{DM}$ is recognised to occur spontaneously within the population, though these patients had been receiving nivolumab for between 4 and 12 months. 
As many MHC-linked and non-MHC-linked genes and genetic regions in humans and mice, determining the susceptibility to autoimmune diseases, have been identified, further work in mice suggests that immunotherapy may precipitate diabetes development in those with these susceptible HLA alleles (8). In humans, there is a preponderance of high risk HLA alleles in individuals who have developed type $1 \mathrm{DM}$ in the context of PD-1 immunotherapy (9), supporting a genetic predisposition to this complication of therapy. The biological plausibility of these drugs inducing diabetes is supported by experimental work where inhibition of the PD-1/PD-L1 interaction rapidly precipitated diabetes in prediabetic non-obese diabetic (NOD) mice, especially in older mice (10). Thus, PD-1 appears to be critical for progression of autoimmune diabetes in susceptible individuals (10).

PD-1 inhibitors, nivolumab and pembrolizumab, have been associated with a high incidence of thyroid dysfunction $(11,12,13)$. Phase 3 studies of nivolumab therapy for malignant melanoma and non-squamous non-small cell lung cancer (4) have reported a frequency for hypothyroidism of $5.6-6.6 \%$ and for thyrotoxicosis of $1.4-1.9 \%$ respectively. Noteworthy, the risk of thyroid abnormalities increases substantially when patients are treated with a combination of PD-1 and CTLA-4 (cytotoxic T-lymphocyte antigen-4) inhibitors $(14,15)$ or when PD-1 inhibitor follows CTLA-4 therapy, such as ipilimumab, especially when the wash-out period is $<4$ weeks (15). The most commonly described types of nivolumab-related thyroid dysfunction are either a transient thyrotoxic phase, which tends to resolve spontaneously and is often followed by hypothyroidism (11) or development of isolated hypothyroidism, both caused by painless thyroiditis (12). Thyrotoxicosis tends to occur within 6 weeks after the first administration of nivolumab. However, the time to onset of hypothyroidism ranges from 4 days to months following initiation of immunotherapy, making it very difficult to predict the occurrence time $(11,12,14,15)$. Finally, it has been suggested that new occurrence of thyroid and extrathyroid autoimmune disorders may be associated with a better treatment response to PD-1 inhibitors $(13,15)$, but this finding needs to be studied further.

A high incidence of positive thyroid peroxidase antibodies (anti-TPO antibodies) and thyroglobulin antibodies (anti-TG antibodies) has been reported in patients with nivolumab-induced thyroid dysfunction $(11,12,13,16)$, while Maekura and coworkers recently suggested that positive anti-TPO and anti-TG antibodies at baseline may predict nivolumab-induced hypothyroidism (16). These data provide evidence for a possible link of immunologic pathways with nivolumab-induced thyroid dysfunction. It is also known that PD-L1 and PD-L2 are expressed in normal thyroid tissue. Consequently, inhibiting the PD-1 pathway could be correlated with reduced immune tolerance and development of thyroiditis (12). In addition, polymorphic variants of the PD-1 receptor gene may be related to the occurrence of painless thyroiditis (11).

The rapidity of onset and profound nature of the diabetic ketoacidosis at presentation in our non-Asian patient, which occurred two months following the commencement of immunotherapy and was followed by the development of hypothyroidism 6 months later, highlight the need for regular patient monitoring in order to promptly identify immune-related endocrinopathies. In addition, clinicians should be aware and warn patients of potential signs and symptoms indicative of hyperglycaemia. In our practice, we monitor glucose levels every 2 weeks during the period of nivolumab therapy. We also educate patients on symptoms of hyperglycaemia and provide them with blood glucose monitor to check glucose levels in case of hyperglycaemic symptoms. Serum concentration of TSH and free T4 is measured prior to and 2-weekly after nivolumab therapy. Moreover, all patients who have already developed a nivolumab-related endocrine adverse event undergo periodical monitoring for other possible endocrinopathies. For example, in our case, we regularly measure early morning serum cortisol in view of the risk for hypophysitis or adrenalitis.

Despite a recent systematic review and meta-analysis of 7551 patients in 38 randomised trials reporting an overall incidence of about 10\% for immunotherapyrelated clinically significant endocrinopathies (17), immunotherapy is usually not discontinued since its favourable outcomes seem to outweigh these adverse events (3). Studies are warranted to identify the risk factors for development of immunotherapy-induced type 1 diabetes (3), but also the frequency and natural history of this adverse event. The same need for prospective studies applies to examining the utility of baseline evaluation of thyroid TPO or/and TG antibodies as a predictor for development of thyroid dysfunction (16). Most importantly, patients and healthcare professionals should be well educated on symptom recognition and management of these endocrinopathies while on immunotherapy. 


\section{Declaration of interest}

The authors declare that there is no conflict of interest that could be perceived as prejudicing the impartiality of the research reported.

\section{Funding}

This research did not receive any specific grant from any funding agency in the public, commercial or not-for-profit sector.

\section{Patient consent}

A written informed consent has been obtained from the patient for publication of the submitted article and accompanying images.

\section{Author contribution statement}

P T was in charge of patient's management, coordinated with the other authors and prepared the final manuscript. R W C was involved in the initial management of the patient, wrote the initial draft of the article and contributed substantially to writing the case report. S P and T D undertook literature review and contributed substantially to writing the case report. E B, D H and J S were actively involved in the immediate and long-term management of the patient.

\section{References}

1 Godwin JL, Jaggi S, Sirisena I, Sharda P, Rao AD, Mehra R \& Veloski C. Nivolumab-induced autoimmune diabetes mellitus presenting as diabetic ketoacidosis in a patient with metastatic lung cancer. Journal for ImmunoTherapy of Cancer 20175 40. (https://doi. org/10.1186/s40425-017-0245-2

2 Li L, Masood A, Bari S, Yavuz S \& Grosbach AB. Autoimmune diabetes and thyroiditis complicating treatment with nivolumab. Case Reports in Oncology 201710 230-234. (https://doi. org/10.1159/000456540)

3 Araújo M, Ligeiro D, Costa L, Marques F, Trindade H, Correia JM \& Fonseca C. A case of fulminant Type 1 diabetes following anti-PD1 immunotherapy in a genetically susceptible patient. Immunotherapy 20179 531-535. (https;//doi.org/10.2217/imt-2017-0020)

4 Borghaei H, Paz-Ares L, Horn L, Spigel DR, Steins M, Ready NE, Chow LQ, Vokes EE, Felip E, Holgado E, et al. Nivolumab versus docetaxel in advanced nonsquamous non-small-cell lung cancer. New England Journal of Medicine 2015373 1627-1639. (https://doi. org/10.1056/NEJMoa1507643)

5 Hughes J, Vudattu N, Sznol M, Gettinger S, Kluger H, Lupsa B \& Herold KC. Precipitation of autoimmune diabetes with anti-PD-1 immunotherapy. Diabetes Care 201538 e55-e57. (https://doi. org/10.2337/dc14-2349)

6 Okamoto M, Okamoto M, Gotoh K, Masaki T, Ozeki Y, Ando H, Anai M, Sato A, Yoshida Y, Ueda S, et al. Fulminant type 1 diabetes mellitus with anti-programmed cell death-1 therapy. Journal of Diabetes Investigation 20167 915-918. (https://doi.org/10.1111/ jdi.12531)

7 Mellati M, Eaton KD, Brooks-Worrell BM, Hagopian WA, Martins R, Palmer JP \& Hirsch IB. Anti-PD-1 and anti-PDL-1 monoclonal antibodies causing type 1 diabetes. Diabetes Care 201538 e137-e138. (https://doi.org/10.2337/dc15-0889)

8 Kochupurakkal NM, Kruger AJ, Tripathi S, Zhu B, Adams LT, Rainbow DB, Rossini A, Greiner DL, Sayegh MH, Wicker LS, et al. Blockade of the programmed death-1 (PD1) pathway undermines potent genetic protection from type 1 diabetes. PLOS ONE 20149 1-11. (https;//doi.org/10.1371/journal.pone.0089561)

9 Chae YK, Chiec L, Mohindra N, Gentzler R, Patel J \& Giles F. A case of pembrolizumab-induced type- 1 diabetes mellitus and discussion of immune checkpoint inhibitor-induced type 1 diabetes. Cancer Immunology, Immunotherapy 201666 1-8. (https;//doi.org/10.1007/ s00262-016-1913-7)

10 Ansari MJ, Salama AD, Chitnis T, Smith RN, Yagita H, Akiba H, Yamazaki T, Azuma M, Iwai H, Khoury SJ, et al. The programmed death-1 (PD-1) pathway regulates autoimmune diabetes in nonobese diabetic (NOD) mice. Journal of Experimental Medicine 2003198 63-69. (https://doi.org/10.1084/jem.20022125)

11 Orlov S, Salari F, Kashat L \& Walfish PG. Induction of painless thyroiditis in patients receiving programmed death 1 receptor immunotherapy for metastatic malignancies. Journal of Clinical Endocrinology and Metabolism 2015100 1738-1741. (https://doi. org/10.1210/jc.2014-4560)

12 Yamauchi I, Sakane Y, Fukuda Y, Fujii T, Taura D, Hirata M, Hirota K, Ueda Y, Kanai Y, Yamashita Y, et al. Clinical features of nivolumabinduced thyroiditis: a case series study. Thyroid 201727 894-901. (https://doi.org/10.1089/thy.2016.0562)

13 Alhusseini M \& Samantray J. Hypothyroidism in cancer patients on immune checkpoint inhibitors with anti-PD1 agents: insights on underlying mechanisms. Experimental and Clinical Endocrinology and Diabetes 2017125 267-269. (https://doi.org/10.1055/s-0042-119528)

14 Morganstein DL, Lai Z, Spain L, Diem S, Levine D, Mace C, Gore M \& Larkin J. Thyroid abnormalities following the use of cytotoxic T-lymphocyte antigen- 4 and programmed death receptor protein-1 inhibitors in the treatment of melanoma. Clinical Endocrinology 2017 86 614-620. (https://doi.org/10.1111/cen.13297)

15 Guaraldi F, La Selva R, Samà MT, D’Angelo V, Gori D, Fava P, Fierro MT, Savoia P \& Arvat E. Characterization and implications of thyroid dysfunction induced by immune checkpoint inhibitors in real-life clinical practice: a long-term prospective study from a referral institution. Journal of Endocrinological Investigation 2017 Epub. (doi:10.1007/s40618-017-0772-1)

16 Maekura T, Naito M, Tahara M, Ikegami N, Kimura Y, Sonobe S, Kobayashi T, Tsuji T, Minomo S, Tamiya A, et al. Predictive factors of nivolumab-induced hypothyroidism in patients with non-small cell lung cancer. In Vivo 201731 1035-1039. (https;//doi.org/10.21873/ invivo.11166)

17 Barroso-Sousa R, Barry WT, Garrido-Castro AC, Hodi FS, Min L, Krop IE \& Tolaney SM. Incidence of endocrine dysfunction following the use of different immune checkpoint inhibitor regimens: a systematic review and meta-analysis. JAMA Oncology 20184 173-182. (https://doi.org/10.1001/jamaoncol.2017.3064) 